\title{
Article
}

\section{Effectiveness of warning graphic labels on cigarette packs in enhancing late-teenagers' perceived fear of smoking-related harms in Bangkok, Thailand}

\author{
Surapong Chudech, Piyapong Janmaimool \\ Department of Social Sciences and Humanities, School of Liberal Arts, King Mongkut's University of Technology \\ Thonburi, Bangkok, Thailand
}

\begin{abstract}
Background: This study investigated the level of fear of smoking-related harms for teenagers of different gender, different levels of smoking behaviour, and difference in smoking levels of friends and family members, as influenced by warning graphic images on cigarette packs. The study also compared levels of this fear in categories based on participants' perception (e.g., scarier or less scary images).

Design and Methods: The sample group was 353 undergraduate students at King Mongkut's University of Technology Thonburi in Bangkok, Thailand. Questionnaires containing 21 warning graphic images, aimed at measuring levels of fear of smoking-related harms, were conducted. Both descriptive statistics and inferential statistics, such as independent and dependent $t$ test, were used to analyse the data.

Results: The results showed that warning graphic images exhibiting patients suffering from cancers (e.g., lung cancer or laryngeal cancer) and images of damaged body parts were perceived as the scariest warning images. In contrast, images that did not illustrate serious disease suffered by smokers were perceived as the least scary images. The scariest images generated a significant higher level of fear of smoking-related harms than the least scary images. In addition, non-smoking participants were more sensitive to scary warning images than smoking participants. It was also found that the level of fear of smoking-related harms was significantly based on individual cognitive judgment, and it was not affected by the influence of social groups such as friends and family members.

Conclusions: Developing effective warning graphic images could directly contribute to individuals' perceived health risks and danger associated with smoking.
\end{abstract}

\section{Introduction}

Tobacco utilization has been ranked as the third cause of death in the world. Frequent inhalation of cigarette smoke toxicants potentially causes both short-term and long-term serious health effects. In the short run, the smoker could have overall diminished health status, particularly being susceptibility to acute illnesses and respiratory symptoms. For the long-term health effects, the smoker might experience diseases that are the major causes of death such as coronary heart disease, cancer, and chronic obstructive pulmonary disease, or COPD. ${ }^{1}$ The World Health Organization $^{2}$ reported that smoking potentially could cause diverse diseases, including 10 types of cancer, respiratory diseases, and 18 additional, relevant diseases. In Thailand, the number of smokers aging over 15 years old is 10.7 million people or $19.1 \%$ of total population with the age over 15 years old. ${ }^{3}$ Though, this number is slightly decreasing compared to other previous years, the number of teenage smokers is increasing, approximately $0.3 \% .^{3}$ In 2018 , the smokers smoked approximately 10 cigarettes per day, and the mean age at initiation of smoking in Thailand was 18.1 years old.

Health warning labels on cigarette packs became an important platform for communicating with smokers and the general public. ${ }^{4}$ For instance, a person who smokes one cigarette pack per day will see warning labels more than 7,000 times per year. In other words, the health warning label is an effective communication channel that is widely and easily accessed by smokers. ${ }^{5}$ Specifically, using warning graphic images together with warning statements presenting potential health impacts was shown to be more effective than using images or statements separately. ${ }^{6-9}$

The guidelines for placing health warning graphic labels on cigarette packs were issued in the Article No. 11 of the WHO Framework Convention on Tobacco Control (WHO FCTC). This act stipulated that cigarette packaging must have warning graphic labels illustrating health risks and potential health effects caused by smoking. The graphic labels could be in the form of an image or a symbol. In addition, a list of compounds found in tobacco and cigarette smoke had to be disclosed to the public. Also, the warning labels had to cover at least $30 \%$ of the front and back of the cigarette pack, and if possible, cover $50 \%$ or more. ${ }^{10}$ Moreover, guidelines for the design of cigarette packs, such as the contents and positions of graphic images, were also stipulated. Currently, there are 180 countries which have ratified this convention. ${ }^{11}$ Consequently, cigarette packs produced in these countries have warning graphic labels about potential health impacts caused by

Significance for public health

Tobacco utilization has been ranked as the third cause of death in the world. The WHO Framework Convention on Tobacco Control stipulated that cigarette packaging must have warning graphic labels illustrating health risks and potential health effects caused by smoking. An understanding of people's perceived health risks and dangers associated with smoking behaviour when seeing warning images on cigarette packs is crucial. This study concluded that the use of smoking warning images on cigarette packs is still necessary and should be continuously developed, to promote smoking cessation or to reduce new smoker rate, particularly among late-teenagers. 
smoking, although the position and content of the labels vary. In 2001, Canada became the first country to implement the use of warning graphic labels on cigarette packs, and the label was $50 \%$ of the total area of the pack. This was larger than the labels used in more than 30 countries that ratified the WHO's convention. ${ }^{12,13}$ In Uruguay, the size of the label was required by law to cover $80 \%$ of the front and back of the cigarette pack. Additionally, many other countries worldwide have increased the size of the warning label on principal display areas.

Thailand is not an exception to this trend. Currently, the size of the warning label on cigarette packs in Thailand is $85 \%$ of the front and back of the packs. ${ }^{14}$ These warning graphic images and statements play an important role in educating smokers or potential smokers about cigarettes. Communicating this information could help enhance health awareness and the perception of the danger caused by smoking. ${ }^{15}$ Diverse warning images have been employed to communicate with the public. However, studies on the effectiveness of these warning images are limited. It is still unclear whether these images could generate people's fear-related emotion and could encourage people to avoid smoking behaviour.

To thoroughly understand the effectiveness of smoking warning images for enhancing target groups' awareness and positively changing smokers' behaviours, particularly among youths, this study investigated the level of fear-related emotions about adverse consequences of smoking as influenced by warning graphic labels on cigarette packs. The results of this study could provide implications for improving smoking warning images on cigarette packs to increase the effectiveness of images that potentially enhance awareness and change smoking behaviours of teenagers.

\section{Research objectives}

This research contains 3 research objectives as follows:

i. To investigate late-teenagers' perception of smoking warning images in terms of the scariness of warning images.

ii. To investigate how smoking warning images which are perceived as the scariest images and the least scary images contribute to late-teenagers' feeling of fear of smoking-related harms.

iii. To investigate whether levels of fear of smoking-related harms, generated from smoking warning images, are influenced by late-teenagers' social and behavioural characteristics including genders, levels of engagement in smoking behaviour, and smoking levels of friends and family members.

\section{Literature review}

\section{Fear of smoking-related harms}

Fear can be defined as an emotion experienced from a serious and personally relevant threat. ${ }^{16}$ Engelbrecht ${ }^{17}$ stated that fear is a chain reaction in the brain that is caused by a stressful stimulus and consequently contribute to the release of chemicals that result in a fast breathing, racing heart and energized muscles, among other things, also known as the fight-or-flight response. In another word, fear can be defined as an unpleasant feeling which is a result of perceived risk or danger. Perceived risk can be real or imaginary. ${ }^{18}$ In short, fear is a negative emotion caused by an individual's perceived threat and danger. According to Dual-process information processing theory, fear, a kind of negative emotion, potentially enhance individuals' desired and appropriate responses to health warning. ${ }^{19,20}$ Many experimental studies in the field of health communication also concluded that negative affective reactions provoked by health warnings cued further warning information processing $^{21}$ and finally contributed to one's decision to permanently quit smoking behaviours. ${ }^{20,22}$ Borgatta and Evans ${ }^{23}$ indicated that individuals having a greater level of fear would be more motivated to adopt anti-smoking attitudes. Similarly, the study of Sutton ${ }^{24}$ revealed a positive relationship between fear and one's acceptance of recommended response behaviour. It can be stated that fear is a driver of behavioural change. In this way, pictorial health warnings on tobacco packaging have been used as a tool to enhance people's feeling of fear and promote negative attitudes toward smoking, motivation to quit smoking behaviour. ${ }^{6}$. The study of Cho et al. ${ }^{25}$ revealed that smokers who had stronger negative emotions (e.g., fear, worry, and disgust) tended to make more quitting attempts at follow-up than those who had lower negative emotions. Smokers' attention to smoking warnings and behavioural responses to images mediated this relationship.

\section{Roles of smoking warning labels in generating fear-related emotion and promoting health awareness}

Many studies have been conducted to investigate the influence of warning graphic labels on smoker's attitudes toward health and quitting behaviours. Those studies conducted both in Thailand and other countries have demonstrated that warning images could help promote smokers' participation in quitting behaviour. ${ }^{26-31}$ Warning images also helped enhance smokers' health awareness, causing them to smoke less than they had previously. ${ }^{26,27}$ Warning images induced negative emotions, such as fear or disgust. Smokers who had intense fear-related emotions tried to quit smoking or tried to smoke less. ${ }^{28,29}$ Some people avoided cigarette packs due to getting negative feelings when seeing the warning images. ${ }^{30}$ Morgan et $a l^{31}$ added warning images could also foster conversations about adverse impacts of smoking behaviours and could finally lead to quit attempts.

One study investigated the influence of six types of warning images on people's perceived risks associated with smoking behaviour. ${ }^{32}$ The results revealed that non-smoking participants reported high perceived health risks associated with smoking behaviours when seeing all six types of warning images. Another study revealed that most smoking and non-smoking participants believed that warning images and statements had some effect on their feelings in terms of motivation to quit smoking or of feeling scared of smoking. ${ }^{33}$

According to the study of Action on Smoking and Health Foundation, ${ }^{34}$ it was found that $30 \%$ of teenage smoking participants had a deterred desire to smoke due to seeing warning graphic labels on cigarette packs. Approximately $42 \%$ of non-smoking participants reported not wanting to try smoking after seeing warning graphic labels on cigarette packs. More than $30 \%$ reported gaining more knowledge about cigarettes from smoking warning labels. ${ }^{34}$ Another relevant study demonstrated that two of three could memorized characteristics of warning images, after seeing those images. ${ }^{35}$ In addition, an image showing a person suffering from laryngeal cancer was the most powerful image that made participants wanted to quit smoking behaviour or deterred desire to try smoking. Meanwhile, an image showing cigarette smoke caused less motivation among participants to quit smoking. Approximately $50 \%$ of participants thought they were equally likely to suffer from a possible disease caused by smoking and not suffer any disease. Approximately 70\% reported that warning images had a high level of influence on the decision to quit smoking, and approximately $50 \%$ of smokers reported that the images made them want to quit smoking. ${ }^{35}$ Another study investigated the influence of each type of warning image on risk perception. ${ }^{36}$ Images relating to cancer patients, such as a chest X-ray of a lifelong smoker or a laryngectomy, contributed to the highest level of perceived risks and feelings of danger associated with cigarettes. Additionally, most people perceived these types of images as the 
scariest labels and most well-recognized images. These findings corresponded to the study conducted by Tobacco Control Research and Knowledge Management Centre, ${ }^{37}$ which revealed that an image exhibiting cigarette smoke causing lung cancer had the most powerful influence on participants' decision to avoid smoking behaviour. A previous study ${ }^{38}$ indicated three factors contributing to the smoking behaviour of teenagers. These factors are demographic characteristics (e.g., gender, age, and place of origin), personal factors (e.g., social norms and social influence generated from smoking behaviour of friends or family members), and environmental factors (e.g., the environment in which people easily access cigarettes or the location of shops selling cigarettes). Of these factors, gender was one of important issues. Male teenagers had a more positive attitude toward smoking behaviour than female teenagers. ${ }^{39,40}$ In addition, male teenagers with low selfesteem tended to engage in smoking behaviour more than female teenagers with low self-esteem, whereas there was a significant difference in the level of smoking behaviours between male and female teenagers with high self-esteem. ${ }^{41}$ Social norms also influenced male and female teenagers' decisions to engage in smoking behaviour; female smokers were more negatively perceived by the public. ${ }^{42}$ Social expectations regarding the ways males and females should behave are different and, therefore, affect the decision to partake in smoking behaviours for each gender.

Social influence generated from friends and family members is also powerful when promoting smoking behaviour. A previous study found that friends and family members' attitudes toward smoking could predict smoking initiation among teenagers. ${ }^{43}$ The attitudes towards cigarettes and smoking behaviours of people surrounding teenagers could predict teenagers' motivation to smoke as well.

\section{The use of smoking warning labels in Thailand}

In Thailand, the Ministry of Public Health is authorized to issue relevant regulations for cigarette packaging and labelling. In 2004, the Ministry of Public Health Notice announced rules, procedures, and conditions for the display of images, warning statements about dangers, and contact channels on cigarette labels. ${ }^{44}$ Consequently, the following six types of images were used as warning labels: 1) images illustrating smoking causing suffering until death due to emphysema, 2) images illustrating smoking causing lung cancer, 3) images illustrating smoking causing sexual dysfunction, 4) images illustrating smoking causing halitosis, 5) images illustrating smoking killing people, and 6) images illustrating smoking hurting kids (Figure 1). Additionally, the warning images were required to cover $50 \%$ of the front and back of cigarette packs. ${ }^{45}$

In 2007, more warning images were added, increasing the types of images from six to nine (Figure 2). ${ }^{46}$ Those nine images included 1) images illustrating that smoking causes death due to pulmonary emphysema, 2) images illustrating that smoking causes halitosis, 3) images illustrating that smoking causes lung cancer, 4) images illustrating that smoking causes rupturing of blood vessels in the brain, 5) images illustrating that smoking causes oral cancer, 6) images illustrating that smoking hurts beloved person, 7) images illustrating that smoking behaviours can kill person, 8) images illustrating that smoking causes larynx cancer, and 9) images illustrating that smoking causes heart attack and death (Figure 2). ${ }^{47}$

In 2009, the warning images were increased from nine to 10 types of images (Figure 3). The size of the warning images was required to cover $55 \%$ of the front and back of the cigarette packs. ${ }^{48}$ In addition, the images were required to provide the phone number of the National Centre for Promoting Smoking Cessation. The statement "smoking can kill you," which was previously required on cigarette packs, was changed to "smoking causes deaths due to heart attack." In 2013, the warning image size required by regulation was changed from $55 \%$ to $85 \%$ of the total display area of cigarette packs, and the inclusion of the phone

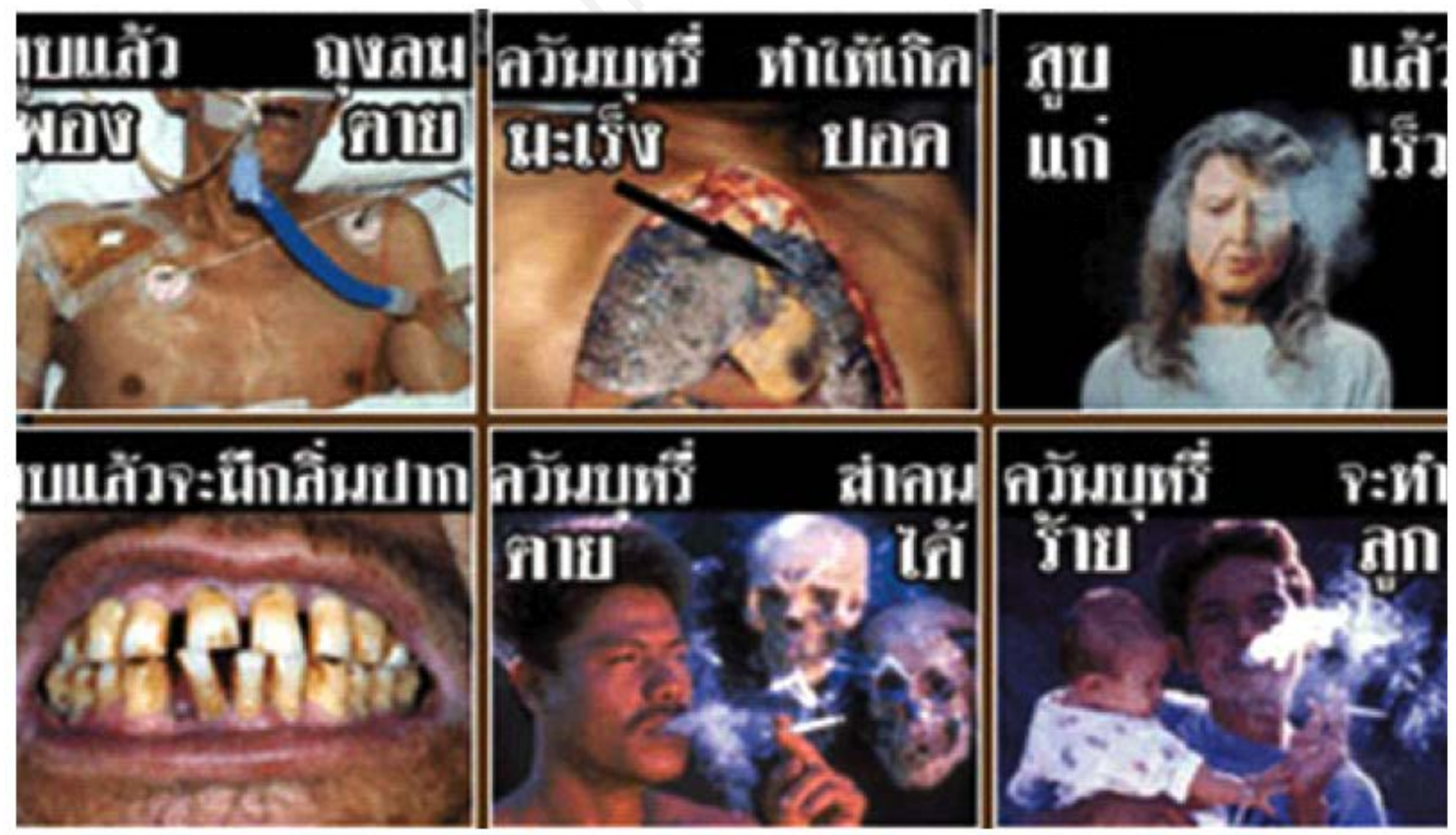

Figure 1. Warning images used in 2004. Source: Kapook.com [Internet] [45]. 
number was also implemented on cigarette advertisements. ${ }^{49}$ Through this change in regulation, Thailand became the country requiring the biggest size of warning images in the world. Ten types of warning images were used on cigarette packs (Figure 4). ${ }^{50}$

In comparison with images used in 2009, several changes were made. The image illustrating that smoking kills beloved person was replaced with the one presenting smoking hurts beloved person such as family members or friends. The image illustrating that smoking causes cerebral ischemia was replaced with an image illustrating that smoking causes cerebrovascular accidents. The image illustrating that smoking causes deaths due to pulmonary emphysema was replaced with the one presenting smoking as causing suffering, until death, from emphysema. More images were added, including the images presenting smoking causing death among kids and smoking causing sexual dysfunction. Changes were also implemented in some images, including the image presenting smoking causing heart attack and the images illustrating that smoking causes oral and lung cancers. These changes in size, image, and statement were implemented over time so that smokers would not become accustomed to the images. When the smokers became accustomed to warning images, their fear-related emotions were not as high, thereby minimizing the effectiveness of the smoking warning labels. ${ }^{39,40}$

\section{Conceptual framework and hypotheses}

This study first investigated the perception of smoking warning images by late-teenagers in terms of the scariness of warning images. Smoking warning images used in this study would be divided into 2 categories (including the scariest warning images and the least scary images) based on participants' judgment. Then, the study examined whether these 2 categories of warning images contributed to a different degree of fear of smoking-related harms. In addition, this study also investigated whether gender, current smoking behaviours, and family and friends' smoking behaviours would affect feelings of fear of smoking-related harms when lateteenagers saw different levels of scariness in smoking warning images.

The independent variables were scariness of smoking warning images, gender, current smoking behaviours, and smoking behaviours of friends and family members, while the level of fear of smoking-related harms was the dependent variable. Smoking warning images that were investigated by this study included the images placed on cigarette packs in Thailand during 2005 to 2013. Four sets of images were developed by the Ministry of Public Health in Thailand during this time. The conceptual framework of this study is shown in Figure $5 .{ }^{51}$ This model was developed form relevant literatures. First, the model exhibited that scariness of smoking warning images positively affects students' perceived fear

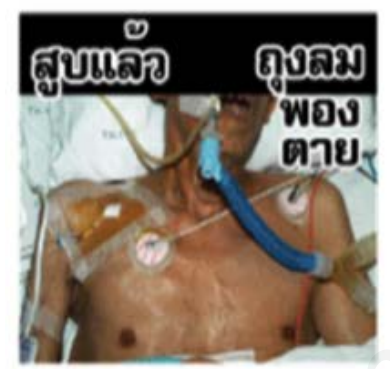

Smoking die from emphysema

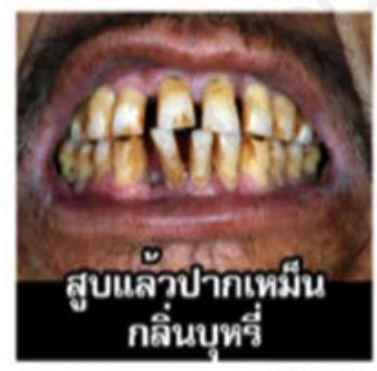

Cigarettes cause bad breath

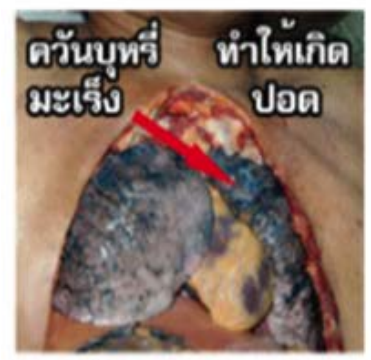

Cigarettes cause lung Cancer

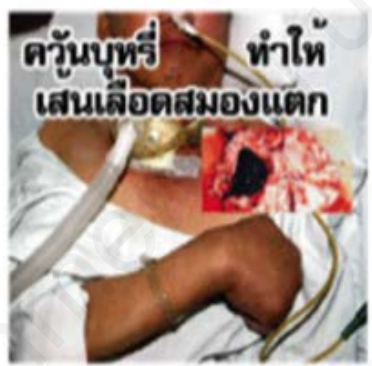

Smoking cause stroke

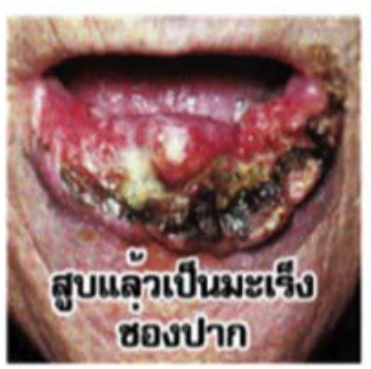

Smoking cause oral cancer

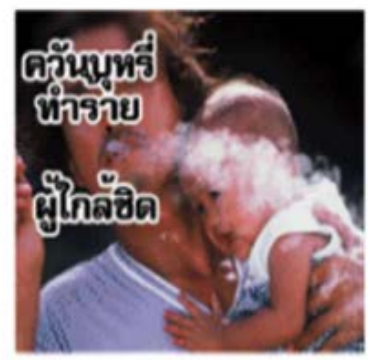

Cigarette smoke harms your babies

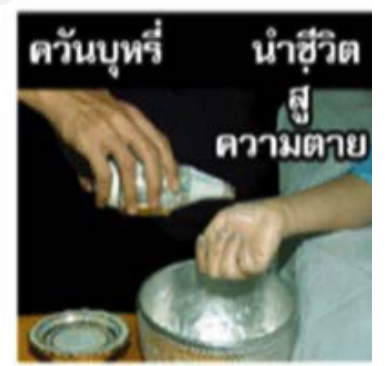

Cigarettes smoke can kill you

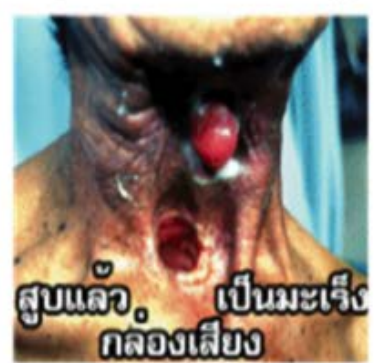

Smoking cause throat cancer

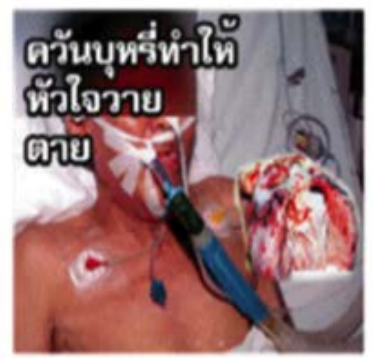

Cigarette smoke cause fatal heart disease

Figure 2. Warning images used in 2007. Source: ttp://ethesisarchive.library.tu.ac.th/thesis/2016/TU_2016_5804010212_6424_4480.pdf [47]. 
of smoking-related harms. ${ }^{35-37}$ Second, social factors and smoking behaviours could have a significant effect on students' perceived fear of smoking-related harms. Those factors are such as gender, ${ }^{38-}$ 40 level of smoking, ${ }^{52,53}$ family members' level of smoking, ${ }^{43}$ friends' level of smoking. ${ }^{43}$ The research hypotheses of this study were as follows:

i. Smoking warning images that were perceived as more gruesome or scary contributed to a higher level of fear of smokingrelated harms than smoking warning images that were perceived as less gruesome or scary.

ii. Late-teenagers who had different social and behavioural characteristics (e.g., gender, level of engagement in smoking behaviour, and friends and family members' level of engagement in smoking behaviour) exhibited different levels of fearrelated emotions when seeing each type of smoking warning images, such as scarier and less scary images.

\section{Research methods}

\section{Participants and data collection}

Participants in this study were undergraduate students at King Mongkut's University of Technology Thonburi in Bangkok,
Thailand, who were enrolled in the academic year of 2016-2017, and registered in a social sciences course. In the academic year of 2016-2017, there were 1,008 students registering in a social sciences course. The size of the sampling population was calculated based on the Yamane formula with a 95\% confidence level. ${ }^{54}$ The results showed that 286 participants were required. A simple random sampling method was applied to select the participants. In the selection of participants, 500 students were invited, and 353 students or approximately $70 \%$ decided to participate in this study. Before the data collection, the students were informed about the research objectives, their roles in this study, and their rights as research participants. Explanations were provided that their given data would be used in this study only, and there were no potential negative effects caused by the participation in this study. In addition, all students also understood that their decision to participate or not would not affect their academic performance evaluation and that they could withdraw from the participation at any time. In presenting the results of this study, no one could identify the participants and their personal information. Instead, the total results of the study would be presented. For the data collection, the students could freely answer questionnaires without teachers' interference. The surveys were conducted during January 2017 to May 2017.

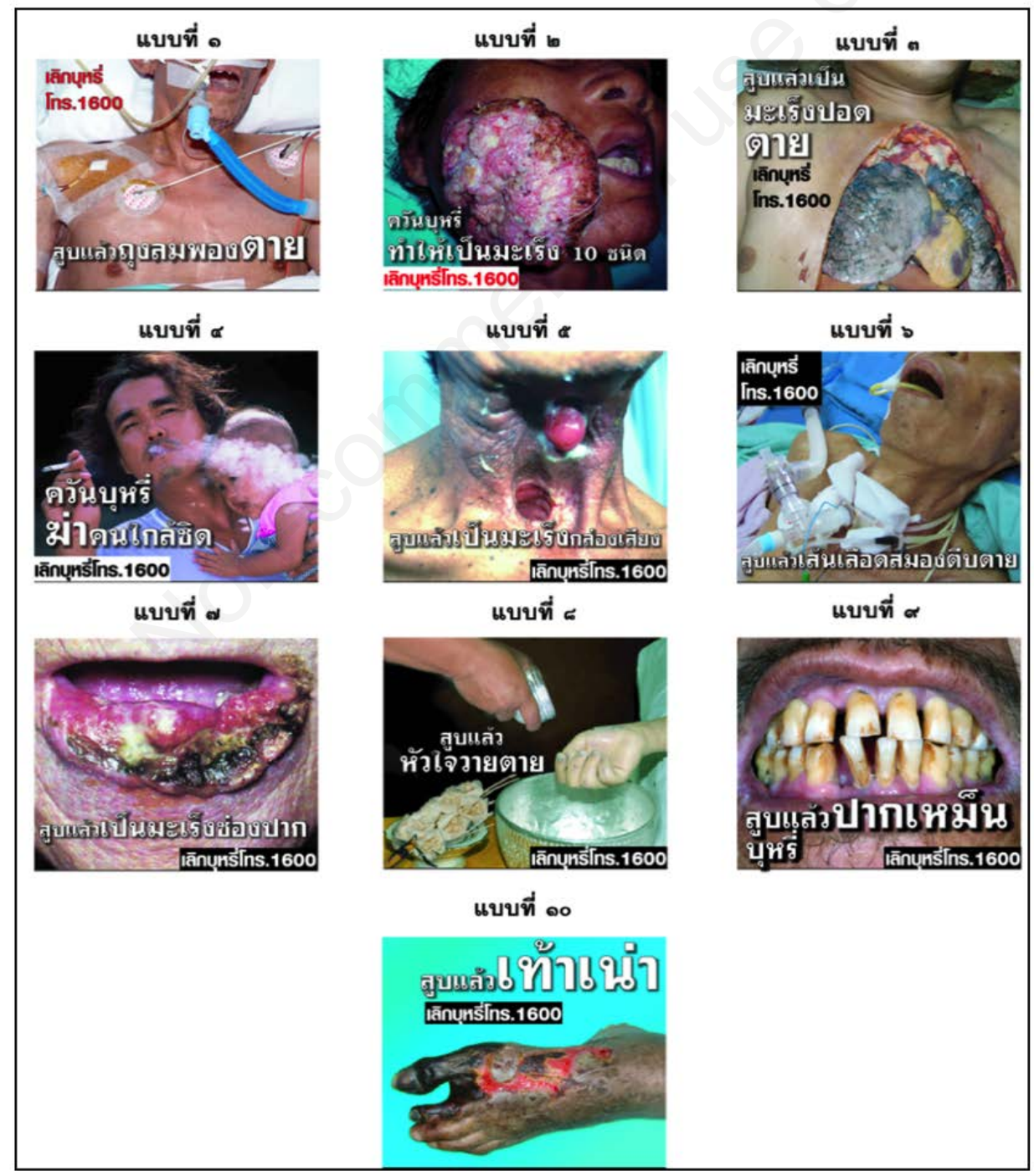

Figure 3. Warning images used in 2009. Source: Family Network Foundation [Internet] [50]. 

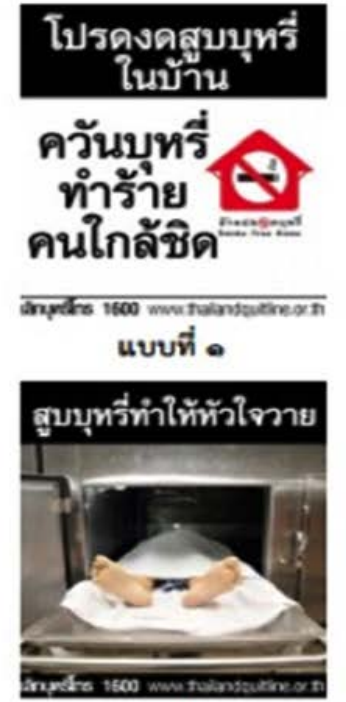

แบบที่ ๔

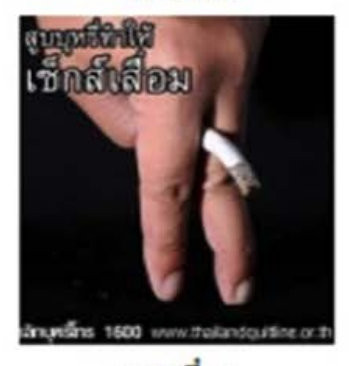

แบบที่ ฮ
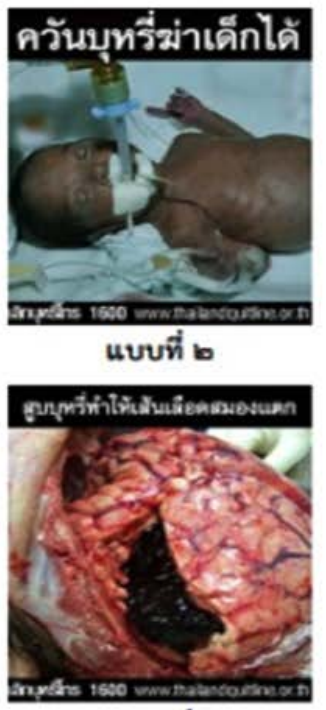

แบบที่ \&

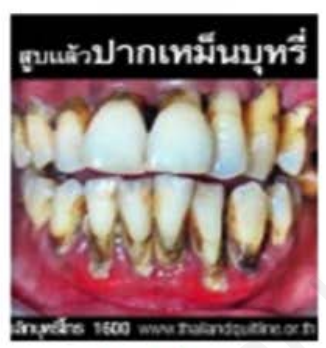

แบบที่ ๔

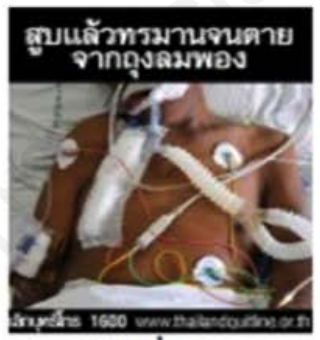

แบบที่ ๑๐

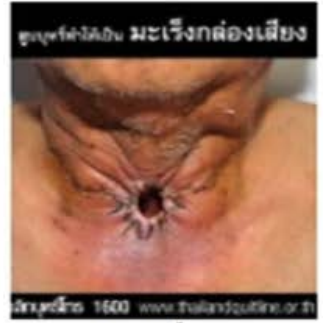

แบบที่ $๓$

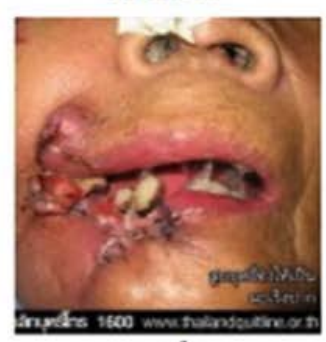

แบบที่ $b$

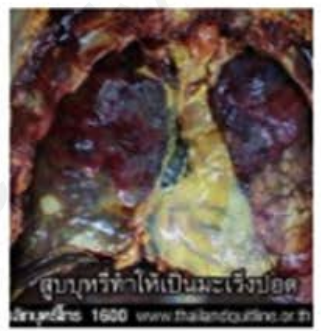

แบบที่ $\alpha$

Figure 4. Warning images used in 2013. Source: Isranews Agency [Internet] [51].

- Perception of scariness of smoking warning images

- Gender

- Level of smoking

- Family members' level of smoking

- Friends' level of smoking

Figure 5. Conceptual framework of the study. 


\section{Research tool}

This study intended to investigate participants' perceived scariness of warning image, and perceived fear of smoking-related harm generated from each warning image. Then, the study compared levels of fear for late-teenagers among different genders, levels of engagement in smoking behaviour, and smoking levels of friends and family members. Questionnaires were used as the research tool. The questionnaires were divided into two parts. The first part aimed at gaining general information about participants, and the second part aimed to measure participants' perception of smoking warning images in terms of the scariness of each warning image, and the level of fear-related emotion influenced by each smoking warning image. Figure 6 presents warning images which have been used to communicate with the public about adverse impacts of cigarettes. ${ }^{55}$ All of these images were included for the analysis in this study.
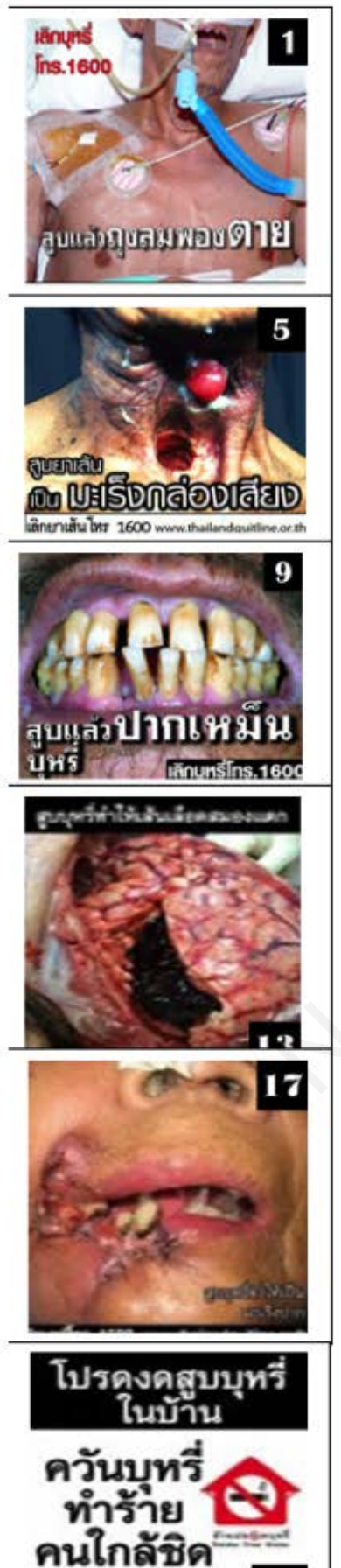
21

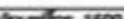
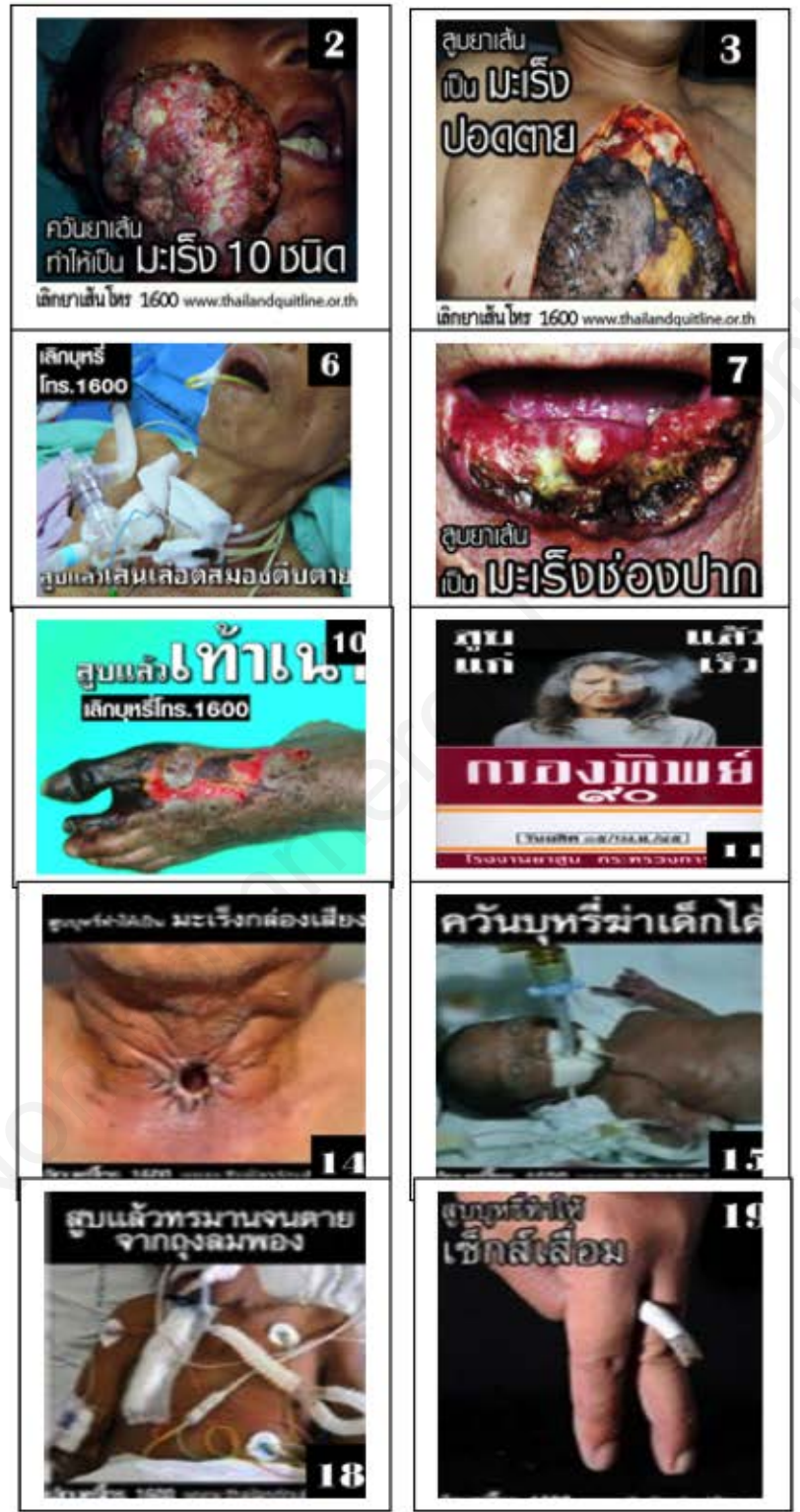
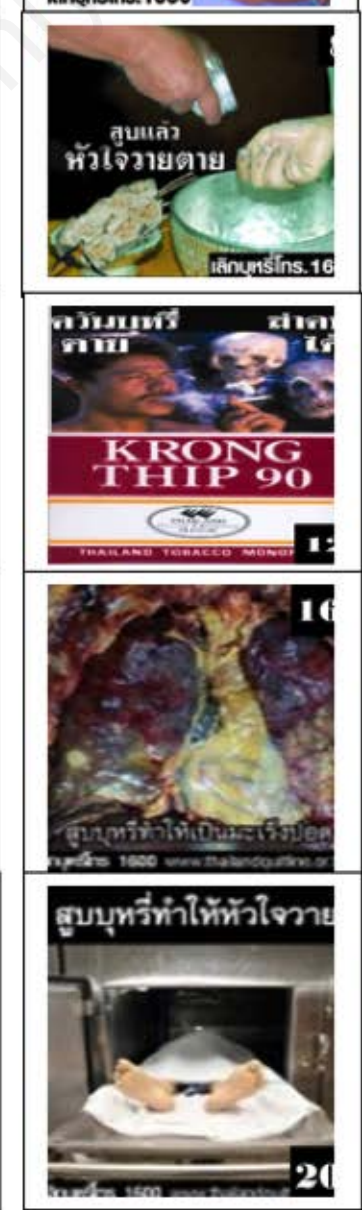

Figure 6. Smoking warning images used to test levels of fear associated with dangers of cigarettes. 
In measuring levels of scariness, and fear of smoking-related harms generated from seeing each image, a measure was developed based on an application of a measure developed by Brown and Smith. ${ }^{56}$ For measuring levels of scariness of warning images, participants were asked to select one image out of 21 images which they perceived as the scariest image, and one image which they perceived as the least scary image. To measure the level of fear of smoking-related harms, participants were asked "how much do each warning image make they feel scared of smoking-related harm". Response scales ranged from not at all (1) to extremely (10). Participants would be asked to evaluate their feelings of fear when seeing each smoking warning image. Many studies also applied this type of question item to measure a feeling of fear of smoking-related harms. ${ }^{57-61}$

To measure participants' smoking behaviour, participants were asked "Do you smoke cigarettes?". Response scales are: (1) not at all; (2) rarely smoke; (3) once a week; (4) more than once a week; and (5) regularly smoke. However, in doing the analysis, participants' smoking behaviour would be classified into 2 groups including no involvement in smoking behaviours and involvement in smoking behaviours. For measuring participants' relationships with friends and family members who are smokers, they were asked whether their family members or any of their friends who had smoked cigarettes.

Participants in this study were undergraduate students at King
Mongkut's University of Technology Thonburi in Bangkok, Thailand, who were enrolled in the academic year of 2016-2017, and registered in social sciences courses. Most of them were in their fourth year at university. An average age of participants was 22 years old. Most of them were from Bangkok city, the capital city of Thailand. Considering participants' fields of study, approximately $40 \%$ were studying engineering, and $20 \%$ or 71 participants were studying science and technology. Participants studying industrial education were accounted for $20 \%$. Approximately $15 \%$ or 53 participants were studying about information technology, and another 5\% was studying arts and media.

\section{Data analysis}

Data analysis was performed using the Statistical Package for the Social Sciences (SPSS) v. 17. First, the internal consistency of the scales, which were developed for measuring levels of fear of smoking-related harms, were tested by calculating Cronbach's alpha. The results showed that the values of Cronbach's alpha were 0.87 . Therefore, the data gain form the surveys was reliable for data analysis. Then, descriptive statistics (mean, standard deviation, and percent) and inferential statistics (both paired samples $t$ test and independent samples $t$-test) were performed to test the research hypotheses. Data analysis included 5 steps as shown in the Figure 7.

\section{Testing the internal consistency of the scale used for measuring levels of fear of smoking-related harms.}

\section{Evaluating the level of scariness of each smoking warning image by calculating} frequency scores which were generated from participants' selection of the scariest warning image and the least scary image.

\section{Selecting 5 images receiving the highest frequency scores and 5 images receiving the lowest frequency scores.}

\section{Calculating total scores of fear-related harm generated from those 5 scariest images and 5 least scary images.}

\section{Performing t-test statistics for testing the research hypotheses.}




\section{Results}

\section{Characteristics of participants}

Of the 353 participants, approximately $56 \%(n=198)$ were female and approximately $44 \%(n=155)$ were male (Figure 1$)$. The lowest age of the participants was 19 years old, and the highest age was 26 years old. Almost $69 \%$, or 242 participants, reported themselves as non-smokers or having never smoked, and 58 participants, or $16.4 \%$, reported having tried to smoke. The number of participants who reported smoking at least once a week was 20 , or $5.7 \% ; 9$ students, or $2.5 \%$, reported smoking more than once a week. Of the students, 24 (6.8\%) reported regularly smoking. The number of participants who had a family member who smoked was 117 , accounting for $33.2 \%$, while 235 students (66.8\%) did not have a family member who smoked. Finally, 241 participants, or $68.5 \%$, had a friend who smoked, while 111 participants, or $31.5 \%$, had no friends who smoked (Table 1).

\section{Levels of scariness of cigarette warning images per- ceived by participants}

In measuring levels of scariness of cigarette warning images, 21 cigarette warning images were shown to participants; then, each participant was asked to select one image out of 21 images which they perceived as the scariest image, and one image which they perceived as the least scary image. After that, frequency was calculated based on the number of times which each image was selected. Therefore, each image would have a different frequency value. In Table 2, the five smoking warning images which most participates selected as the scariest images included image no. 13, $3,5,16$, and 1 , and the five images that most participants selected as the least scary included no. $21,11,19,9$, and 12 .

\section{Levels of fear of smoking-related harms influenced by smoking warning images}

Smoking warning images were divided into two categories, including images perceived as the scariest images (no. 13, 3, 5, 16, and 1) and images perceived as the least scary images (no. 21, 11,

Table 1. Characteristics of the survey participants.

\begin{tabular}{llcc} 
& & n & Percentage \\
\multirow{4}{*}{ Gender } & Male & 155 & $44 \%$ \\
& Female & 198 & $56 \%$ \\
& 19 & 5 & $1.4 \%$ \\
& 20 & 22 & $6.2 \%$ \\
& 21 & 75 & $21.2 \%$ \\
& 22 & 192 & $54.4 \%$ \\
& 23 & 39 & $11 \%$ \\
& 24 & 13 & $3.7 \%$ \\
& 25 & 4 & $1.1 \%$ \\
& 26 & 3 & $0.8 \%$ \\
\hline \multirow{2}{*}{ Smoking behaviour } & Never smoke & 242 & $68.6 \%$ \\
& Rarely smoke & 58 & $16.4 \%$ \\
& Smoke once a week & 2 & $5.7 \%$ \\
& Smoke more than once a week & 9 & $2.5 \%$ \\
& Regularly smoke & 24 & $6.8 \%$ \\
Family member's & No involvement in smoking & 235 & $66.8 \%$ \\
smoking behaviour & behaviour & & \\
& Involvement in smoking & 117 & $33.2 \%$ \\
& behaviour & & \\
\hline Friend's smoking & No involvement in smoking & 111 & $31.5 \%$ \\
behaviour & behaviour & & \\
& Involvement in smoking & 241 & $68.5 \%$ \\
& behaviour & & \\
\hline
\end{tabular}

Table 2. Frequency and the rank of smoking warning images that are selected as the scariest image and the least scary image.

\begin{tabular}{|c|c|c|c|c|}
\hline Image no. & Frequency & $\begin{array}{l}\text { Images perceived } \\
\text { as the scariest image (Ranking) }\end{array}$ & Frequency & $\begin{array}{l}\text { Images perceived } \\
\text { as the least scary image (Ranking) }\end{array}$ \\
\hline 1 & 21 & 5 & 4 & 8 \\
\hline 2 & 9 & 8 & 0 & 0 \\
\hline 3 & 54 & 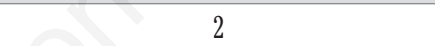 & 2 & 9 \\
\hline 4 & 4 & ( & 15 & 6 \\
\hline 5 & 42 & 3 & 1 & 10 \\
\hline 6 & 7 & 11 & 1 & 10 \\
\hline 7 & 10 & 8 & 0 & 0 \\
\hline 8 & 1 & 15 & 2 & 9 \\
\hline 9 & 15 & 7 & 22 & 4 \\
\hline 10 & 5 & 12 & 1 & 10 \\
\hline 11 & 0 & 0 & 61 & 2 \\
\hline 12 & 3 & 14 & 17 & 5 \\
\hline 13 & 60 & 1 & 2 & 9 \\
\hline 14 & 16 & 6 & 0 & 0 \\
\hline 15 & 8 & 8 & 0 & 0 \\
\hline 16 & 27 & 4 & 2 & 9 \\
\hline 17 & 16 & 6 & 1 & 10 \\
\hline 18 & 8 & 10 & 0 & 0 \\
\hline 19 & 5 & 12 & 54 & 3 \\
\hline 20 & 8 & 10 & 7 & 7 \\
\hline 21 & 3 & 14 & 131 & 1 \\
\hline
\end{tabular}


19, 9, and 12). Then, the total scores of fear of smoking-related harms generated from each category were calculated. The difference in mean scores of fear of smoking-related harms generated from the scariest images and the least scary images was analysed by performing a paired-samples $t$-test (Table 2). The result revealed that the scariest images generated significantly higher levels of fear of smoking-related harms $(\mathrm{M}=35.65, \mathrm{SD}=10.25)$ than the least scary images $(\mathrm{M}=22.15, \mathrm{SD}=11.15), \mathrm{t}(331)=24.13$, $\mathrm{p}=0.000$ (Table 3).

\section{Difference in levels of fear of smoking-related harms influenced by different genders, smoking behaviours, and friends and family members' smoking behaviours}

To examine the difference in levels of fear of smoking-related harms influenced by different genders, smoking behaviours, and friends and family members' smoking behaviours, independent $t$ test was performed. Considering gender difference, the results revealed that, when seeing images perceived as the scariest warning images, female participants reported a significantly higher level of fear of smoking-related harms $(\mathrm{M}=37.47, \mathrm{SD}=9.05)$ than male participants $(\mathrm{M}=34.24, \mathrm{SD}=10.91)$, with a statistically significant level at 0.05 . However, when seeing images that were perceived as the least scary, no significant difference was shown in the levels of fear reported by male and female participants (Table 4).

When considering smoking behaviour of participants, the results revealed that, when seeing images perceived as the scariest warning images, participants who had never smoke reported a higher level of fear of smoking-related harms $(M=37.04, S D=9.19)$ than participants who had smoked $(\mathrm{M}=32.75, \mathrm{SD}=11.69)$, at a statistically significant level of 0.05 . In consideration of images that were perceived as the least scary warning images, no significant difference was found in levels of fear reported by non-smoking participants and smoking participants. Comparing levels of fear reported by participants with family members who were smokers or non-smokers, the results revealed that, when seeing images perceived as the scariest warning images, participants having family members who smoked and participants with no family members who smoked did not report a significantly different level of fear of smoking-related harms. Similarly, in consideration of images that were perceived as the least scary warning images, no significant difference in levels of fear was reported by participants with family members who were smokers or non-smokers.

Considering the smoking behaviour of participants' friends, the results revealed that, when seeing images perceived as the scariest warning images, both participants who had a smoker or non-smoker as a friend did not report a significantly different level

Table 3. Levels of fear of smoking-related harms generated from the scariest warning images and the least scary warning images.

\begin{tabular}{lccccccc} 
Levels of fear of smoking-related harms & $\mathrm{n}$ & $\mathrm{M}$ & $\mathrm{SD}$ & $\mathrm{df}$ & $\mathrm{t}$ & $\mathrm{p}$ \\
Images perceived as the scariest images & 332 & 35.65 & 10.25 & 331 & 24.13 & .000 \\
\hline Images perceived as the least scary images & 332 & 22.15 & 11.40 & & & & \\
\hline
\end{tabular}

Table 4. Average scores of the level of fear of smoking-related harms reported by participants with different social and behavioural characteristics.

\begin{tabular}{|c|c|c|c|c|c|c|}
\hline $\begin{array}{l}\text { Variables } \\
\text { Seeing images perceived as the scariest images }\end{array}$ & n & M & SD & df & $\mathrm{t}$ & p \\
\hline $\begin{array}{l}\text { Gender } \\
\quad \text { Male } \\
\text { Female }\end{array}$ & $\begin{array}{l}187 \\
145\end{array}$ & $\begin{array}{l}34.24 \\
37.47\end{array}$ & $\begin{array}{c}10.91 \\
9.05\end{array}$ & 330 & -2.88 & 0.004 \\
\hline $\begin{array}{l}\text { Levels of involvement in smoking behaviour } \\
\text { No involvement in smoking behaviour } \\
\text { Involvement in smoking behaviour }\end{array}$ & $\begin{array}{l}224 \\
108\end{array}$ & $\begin{array}{l}37.04 \\
32.75\end{array}$ & $\begin{array}{c}9.19 \\
11.69\end{array}$ & 330 & 3.34 & 0.001 \\
\hline $\begin{array}{l}\text { Family member's smoking behaviour } \\
\text { Smoking } \\
\text { Not smoking }\end{array}$ & $\begin{array}{l}111 \\
220\end{array}$ & $\begin{array}{l}35.69 \\
35.58\end{array}$ & $\begin{array}{c}11.24 \\
9.74\end{array}$ & 329 & 0.94 & 0.920 \\
\hline $\begin{array}{l}\text { Friend's smoking behaviour } \\
\text { Smoking } \\
\text { Not smoking }\end{array}$ & $\begin{array}{l}230 \\
101\end{array}$ & $\begin{array}{l}34.92 \\
37.20\end{array}$ & $\begin{array}{c}10.66 \\
9.10\end{array}$ & 329 & -1.87 & 0.060 \\
\hline Seeing images perceived as the least scary image & & & & & & \\
\hline $\begin{array}{l}\text { Gender } \\
\quad \text { Male } \\
\text { Female }\end{array}$ & $\begin{array}{l}187 \\
145\end{array}$ & $\begin{array}{l}21.51 \\
22.97\end{array}$ & $\begin{array}{l}11.69 \\
11.01\end{array}$ & 330 & -1.15 & 0.240 \\
\hline $\begin{array}{l}\text { Levels of involvement in smoking behaviour } \\
\text { No involvement in smoking behaviour } \\
\text { Involvement in smoking behaviour }\end{array}$ & $\begin{array}{l}224 \\
108\end{array}$ & $\begin{array}{l}22.48 \\
21.48\end{array}$ & $\begin{array}{l}11.32 \\
11.60\end{array}$ & 330 & 0.74 & 0.450 \\
\hline $\begin{array}{l}\text { Family member's smoking behaviour } \\
\text { Smoking } \\
\text { Not smoking }\end{array}$ & $\begin{array}{l}111 \\
220\end{array}$ & $\begin{array}{l}22.85 \\
21.70\end{array}$ & $\begin{array}{l}12.24 \\
10.90\end{array}$ & 329 & 0.86 & 0.380 \\
\hline $\begin{array}{l}\text { Friend's smoking behaviour } \\
\text { Smoking } \\
\text { Not smoking }\end{array}$ & $\begin{array}{l}230 \\
101\end{array}$ & $\begin{array}{l}22.07 \\
22.13\end{array}$ & $\begin{array}{l}11.46 \\
11.18\end{array}$ & 329 & -.04 & 0.960 \\
\hline
\end{tabular}


of fear of smoking-related harms. Similarly, when seeing images perceived as the least scary, participants who had a smoker or nonsmoker as a friend did not report a significantly different level of fear.

\section{Discussion and Conclusion}

Smoking warning images reported by participants as causing a high level of fear were mostly related to images exhibiting smokers' suffering in several types of cancers, such as larynx cancer and lung cancer, and images presenting diseased body parts. This finding was consistent with previous studies that found that images of smokers' suffering from cancers were powerful to construct people's perceived risks associated with smoking and perceived smoking-related harm. ${ }^{50,62}$ For example, an image of a smoker's suffering from larynx cancer potentially deterred smokers' desire to smoke and encouraged them to quit smoking. It deterred new potential smokers from initiating smoking behaviour. ${ }^{28,36,37}$ Cancers are a type of disease which most people are scared of due to difficulty in providing a medical cure, and the number of deaths caused by cancers was ranked as the first in Thailand. The proportion of deaths caused by cancers per population was 113.7 deaths/100,000 person. ${ }^{63}$ This could be the root cause of fear of smoking-related harms caused by warning images exhibiting diseased body parts. ${ }^{62}$

Conversely, this study found that images that contributed low levels of fear of smoking-related harms were images that did not exhibit severity of diseases. Those images included images exhibiting that smoking causes sexual dysfunction, halitosis, and premature aging. Images that did not exhibit the concrete effects of adverse consequences caused by smoking also did not enhance people's perceived risks of smoking-related harms. Those images included images illustrating that smoking hurts beloved person or that smoking potentially kills smokers. These types of images did not reflect concretely or physically adverse consequences of smoking. When considering the level of fear of smoking-related harms reported by participants who smoked and did not smoke, the results revealed that, when seeing images perceived as the scariest warning images, participants who did not smoke exhibited a significantly higher level of fear than participants who smoked. For the images that were perceived as the least scary images, participants who did not smoke and did smoke did not show significantly different levels of fear. This implied that smoking warning images had an effect on the level of fear of smoking-related harms, ${ }^{27,30,64}$ particularly in groups of people who did not smoke. ${ }^{52,53}$ In other words, people who did not smoke had more awareness of the dangers caused by cigarettes and smoking behaviours than people who did smoke. When they saw smoking warning images that contained scary images, non-smokers perceived more risks and constructed more feelings of fear than smokers did. For less scary images, non-smokers and smokers did not show a significantly different level of fear. This implied that only warning labels that contained scarier images promoted people's perceived risks associated with cigarette and smoking behaviours.

Regarding gender, female participants constructed more feelings of fear than male participants did when seeing images that were perceived as the scariest images. There was no significant difference in the levels of fear constructed by males and females when both groups saw images that were perceived as the least scary images. This finding was consistent with a previous study by Hammond et al. ${ }^{30}$ that found that the use of smoking warning images would be more effective for enhancing risk perception among females rather than males, but the level of scariness of the images on cigarette packs must be sufficiently high. Similarly, the study by Smith et al. ${ }^{65}$ also demonstrated that females constructed a significantly higher level of fear of the dangers associated with smoking than males did. In addition, females had less participation in risky behaviours than males. ${ }^{65}$ For this study, though female participants reported a statistically significant higher fear than male participants reported, the scores reported by both groups was not greatly different. Therefore, using gruesome and scary warning images for preventing new smokers who are males and females can be recommended. However, it will be more successful, if future research can reveal types of warning images which are powerful to create males' feeling of fear in smoking related harms in particular.

In a similar pattern, participants who did not engage in smoking behaviours reported a significantly higher level of fear of smoking-related harms than participants who engaged in smoking behaviour when seeing warning images that were perceived as the scariest images. No significant difference was found in the levels of fear constructed by non-smoking participants and smoking participants when both groups saw images that were perceived as the least scary images. A previous study also reported similar findings, which indicated that non-smoking participants tended to construct a significantly higher level of perceived risks and dangers associated with smoking than smoking participants. ${ }^{32}$ Therefore, using gruesome and creepy images on cigarette packs potentially deterred vulnerable groups from trying to smoke, leading to minimization of the number of new smokers. Moreover, using these images also helped encourage current smokers to decide to quit smoking behaviours. To create smoking prevention campaigns, educating teenagers with severe health impacts caused by smoking and exhibiting gruesome and scary warning images such as images showing smokers' suffering in several types of cancers and images presenting diseased body parts can lead to the success of campaigns. However, it should be noted that late teenagers who have already participated in smoking behaviours may construct less feeling of fear in smoking related harms. Future studies which can reveal types of warning images that promote feeling of fear in smoking related harms among smoking teenagers are recommended. In consideration of social influence, the results revealed that it did not matter whether participants had a smoking family member or not; no statistically significant difference in levels of fear was found between these two groups when seeing the scariest or the least scary images. With regard to the influence of smoking behaviours of friends, the results showed that whether participants had a smoking friend or non-smoking friend, they reported the same levels of fear of smoking-related harms when seeing both the scariest images and the least scary images. These results implied that the smoking behaviour of family members and friends did not influence people's perception of the dangers associated with cigarette smoking when they saw warning images containing varying level of scariness. The participants' perception was solely based on individual cognitive judgment. In addition, participants who were late teenagers are known to involve in risky behaviours and generally underestimate the risk associated with smoking. It can be highlighted that smoking warning images played an important role in shaping people's risk perception, and social influence did not interfere with these images. Only gender and smoking behaviours of populations should be taken into consideration when a decision to use smoking warning images for promoting smoking cessation or reducing new smoker rate, is made.

In sum, this study provided an understanding of people's perceived health risks and dangers associated with smoking behaviour when seeing warning images on cigarette packs, showing how this perception was merely based on individuals' cognitive judgment. 
No interference of social influence was found in people's constructions of risk perception. In addition, warning images exhibiting scariness and seriousness of disease caused by smoking, such as cancer-diseased body parts, potentially contributed to people's highly perceived risks and dangers associated with smoking. To enhance university students' level of perceived risks associated with smoking, the use of images exhibiting smokers suffering from several types of cancers or diseased body parts will be powerful. Finally, this study concluded that the use of smoking warning images on cigarette packs is still necessary and should be continuously developed. The result of this study could be applied to promote smoking cessation or to reduce new smoker rate, particularly among late-teenagers.

Correspondence: Surapong Chudech, Department of Social Sciences and Humanities, School of Liberal Arts, King Mongkut's University of Technology Thonburi, 126 Prachauthit Road, Thungkru District, Bangkok 10140, Thailand. E-mail: surapong.chu@kmutt.ac.th

Key words: Smoking behaviours; warning graphic images on cigarette packs; fear of smoking-related harms; health risk perception.

Contributions: All the authors made a substantive intellectual contribution. All the authors have read and approved the final version of the manuscript and agreed to be accountable for all aspects of the work.

Conflict of interest: The authors declare no conflict of interest.

Acknowledgments: The authors would like to thank all students who participated in the questionnaire surveys. Publishing is supported by the Research, Innovation, and Partnerships Offices, King Monkut's University of Technology Thonburi, Bangkok, Thailand.

Ethics approval and consent to participate: All procedures performed in studies involving human participants were in accordance with the ethical standards of the Institutional Research Committee of the Research, Innovation, and Partnerships Offices, King Monkut's University of Technology Thonburi, Bangkok, Thailand and with the 1964 Helsinki declaration and its latest amendment. Explanations were provided to participants that their given data would be used in this study only. The results presented do not contain any individual person's data in any form.

Availability of data and materials: The datasets used and/or analyzed during the current study are available from the corresponding author on reasonable request.

Received for publication: 25 August 2020.

Accepted for publication: 12 December 2020

o Copyright: the Author(s), 2021

Licensee PAGEPress, Italy

Journal of Public Health Research 2021;10:1912

doi:10.4081/jphr.2021.1912

This work is licensed under a Creative Commons Attribution NonCommercial 4.0 License (CC BY-NC 4.0).

\section{References}

1. Committee on the Public Health Implications of Raising the Minimum Age for Purchasing Tobacco Products, Board on Population Health and Public Health Practice, Institute of Medicine, et al. Public Health Implications of Raising the Minimum Age of Legal Access to Tobacco Products. Washington DC: National Academies Press (US). 2015. Available from: https://www.ncbi.nlm.nih.gov/books/
NBK310413/

2. World Health Organization. WHO report on the global tobacco epidemic, 2017: monitoring tobacco use and prevention policies. World Health Organization. Available from: https://apps.who.int/iris/handle/10665/255874

3. Tobacco Control Research and Knowledge Management Center. Report on Tobacco Use in Thailand, Mahidol University, Thailand. 2018. Available form: http://www. trc.or.th/th/media/attachments/2562/01/29/2561.pdf

4. Hammond D. Health warning messages on tobacco products: A review. Tob Control 2011;20:327-37.

5. Wakefield M, Morley C, Horan JK. The cigarette pack as image: new evidence from tobacco industry documents. Tob Control 2002;11:73-80.

6. Noar SM, Hall MG, Francis DB, et al. Pictorial cigarette pack warnings: A meta-analysis of experimental studies. Tob Control 2016;25:34-54.

7. Noar SM, Francis DB, Bridges C, et al. The impact of strengthening cigarette pack warnings: Systematic review of longitudinal observational studies. Soc Sci Med 2016;164:118-29.

8. Thrasher JF, Swayampakala K, Hammond D, et al. Influences of self-efficacy, response efficacy and reactance on responses to cigarette health warnings: A longitudinal study of adult smokers in Australia and Canada. Health Commun 2016;31: 1517-26.

9. Mutti-Packer S, Reid JL, Thrasher JF, et al. The role of negative affect and message credibility in perceived effectiveness of smokeless tobacco health warning labels in Navi Mumbai, India and Dhaka, Bangladesh: A moderated-mediation analysis. Addict Behav 2017;73:22-9.

10. WHO. WHO Framework Convention on Tobacco Control (WHO FCTC) Framework Convention on Tobacco Control. Elaboration of Guidelines for Implementation of Article 11 of the Convention. 2008. Available from: http://apps.who.int/gb/ fctc/PDF/cop3/FCTC_COP3_7-en.pdf

11. World Health Organization. WHO Framework Convention on Tobacco Control (WHO FCTC). 2020. Available at: https://www.euro.who.int/en/health-topics/disease-prevention/tobacco/publications/key-policy-documents/who-framework-convention-on-tobacco-control-who-fctc

12. Hammond D, Thrasher J, Reid JL, et al. Perceived effectiveness of pictorial health warnings among Mexican youth and adults: a population-level intervention with potential to reduce tobacco-related inequities. Cancer Causes Control 2012;23:5767.

13. World Health Organization. WHO Report on the Global Tobacco Epidemic, Warning about the Dangers of Tobacco. 2011. Available from: https://www.who.int/tobacco/ global_report/2011/implementation_effective_measures.pdf?u $\mathrm{a}=1$

14. Tobacco Control Laws [Internet]. Legislation by Country. Available from: www.tobaccocontrollaws.org

15. Brewer NT, Hall MG, Noar SM, et al. Effect of pictorial cigarette pack warnings on changes in smoking behavior. A randomized clinical trial. JAMA Intern Med 2016;176:905-12.

16. Yzer MC, Southwell BG, Stephenson MT. Inducing fear as a public communication campaign strategy. In: RE Rice and CK Atkin, editors. Public communication campaigns. Thousand Oaks: Sage; 2012. p. 163-76.

17. Engelbrecht R. Choose Life or Death: Guarding the Gates. Lulu.com; 2019.

18. Lang PJ. Cognition in emotion: Concept and action. In: CE Izard, J Kagan and RB Zajonc, editors. Emotions, cognition, and behavior. Cambridge: Cambridge University Press; 1984. 
p. $192-226$.

19. Borland R. Understanding hard to maintain behaviour change: a dual process approach. J. Wiley \& Sons; 2014.

20. Peters E, Evans AT, Hemmerich N, Berman M. Emotion in the law and the lab: the case of graphic cigarette warnings. Tob Regul Sci 2016;2:404-13.

21. Evans AT, Peters E, Shoben AB, et al. Cigarette graphic warning labels increase both risk perceptions and smoking myth endorsement. Psychol Health 2018;33:213-34.

22. Evans AT, Peters E, Strasser AA, et al. Graphic warning labels elicit affective and thoughtful responses from smokers: Results of a randomized clinical trial. PLoS One 2015;10:e0142879.

23. Borgatta EF, Evans RR. Smoking Health and Behavior. Aldine: Chicago; 1968.

24. Sutton S. Shock tactics and the myth of the inverted U. Br J Addict 1992;87:517-9.

25. Cho YJ, Thrasher JF, Yong H-H, et al. Path analysis of warning label effects on negative emotions and quit attempts: A longitudinal study of smokers in Australia, Canada, Mexico, and the US. Soc Sci Med 2018;197:226-34.

26. Macy JT, Chassin L, Presson CC, Yeung E. Exposure to graphic warning labels on cigarette packages: Effects on implicit and explicit attitudes towards smoking among young adults. Psychol Health, 2015;31:349-63.

27. Canada Cancer Society [Internet]. Evaluation of new warning on cigarette packages highlight. 2002. Accessed: 12 Apr 2018. Available from: http://www.cancer.ca

28. Szklo AS, Volchan E, Thrasher JF, et al. Do more graphic and aversive cigarette health warning labels affect Brazilian smokers' likelihood of quitting? Addict Behav 2016;60:209-12.

29. Yong H-H, Borland R, Thrasher JF, et al. Mediational pathways of the impact of cigarette warning labels on quit attempts. Health Psychol 2014;33:1410-20.

30. Hammond D, Fong GT, McDonald PW, et al. Graphic Canadian cigarette warning labels and adverse outcomes: Evidence from Canadian smoker. Am J Public Health 2004;94:1442-5.

31. Morgan JC, Golden SD, Noar SM, et al. Conversations about pictorial cigarette pack warnings: Theoretical mechanisms of influence. Soc Sci Med 2018;218:45-51.

32. Chalearnchatri P. Effects of smoking warning images on cigarette packs on perception and intention to smoke among people with the age of fifteen years old and above in Nakornsritammarat Province. 2007. [Thesis in Thai]. Master's Thesis, Mahidol University, Thailand.

33. Positioning Magazine [Internet]. Thai people's smoking behavior. New World No Tobacco Day. 2005. [In Thai]. Accessed: 12 Dec 2018. Available from: http://www.positioningmag.com/prnews/prnews.aspx?id=33539

34. Action on Smoking and Health [Internet]. Smoking warning statement on cigarette packs in Thailand. 2008. [In Thai]. Accessed: 12 Dec 2018. Available from: http://dpc9.ddc.moph.go.th/group/ncd/TOBAC\%20ALC/thaiwarninghealth.doc

35. The ABAC Social Innovation in Management and Business Analysis. Survey on Teenagers' opinion on smoking warning images and smoking behaviors. [In Thai]. Assumption University: Bangkok; 2008.

36. Wannasirorat T. Effects of smoking warning labels on health perception of vocational students in Bangkok city. [in Thai]. Master's Thesis, Mahidol University, Thailand: 2010.

37. Tobacco Control Research and Knowledge Management Center. Changes of smoking warning images on cigarette packs and outcome evaluation. 2009. [In Thai]. Accessed: 15
Dec 2018. Available from: http://www.trc.or.th/th/research knowledge/knowledge/knowledge_02.php\#data

38. Evans WD, Powers A, Hersey J, Renaud J. The influence of social environment and social image on adolescent smoking. Health Psychol 2006;25:26.

39. Lim KH, Sumarni MG, Amal NM, et al. Tobacco use, knowledge and attitude among Malaysians age 18 and above. Trop Biomed 2009;26:92-9.

40. Flay B, Phil D, Hu F, Richardson J. Psychosocial predictors of different stages of cigarette smoking among high school students. Prev Med 1998;27:9-18.

41. Hale WJ, Perrotte JK, Baumann MR, Garza RT. Low selfesteem and positive beliefs about smoking: a destructive combination for male college students. Addict Behav 2015;46:949.

42. Hermalin AI, Lowry D. The age prevalence of smoking among Chinese women: A Case of arrested diffusion? Population Studies Center, University of Michigan Ann Arbor; 2010. Available from: https://www.psc.isr.umich.edu/pubs/pdf/rr10718.pdf

43. Sherman S, Chassin L, Sherman J, et al. Social psychological factors in adolescent and adult smoking: Findings and conclusions from a 30-year longitudinal study. Health Commun 2016;3:1517-26.

44. Indonesia Ministry of Public Health. Announcement No.8 B.E. 2547 on rules, procedures and conditions of cigarette labelling and label content according to the Tobacco Products Control Act B.E. 2535. 2004. Available from: https://www.tobaccocontrollaws.org/files/live/Thailand/Thailand \% 20 \%202004\%20P\%26L\%20Rules.pdf

45. Kapook.com [Internet]. Smoking Warning Images. 2004. [In Thai]. Accessed: 17 Apr 2018. Available from: https://hilight. kapook.com/view/116940

46. Indonesia Ministry of Public Health. Notification No. 132550 (A.D. 2007) Re: Criteria, procedures and conditions for displaying pictorial labels and statements of warning on harm of cigars issued under the Tobacco Products Control Act B.E. 2535 (A.D. 1992). 2007-02-27. Available from: https://www.tobaccocontrollaws.org/files/live/Thailand/Thaila nd\%20-\%20Cigar\%20Label\%20Regs\%202007.pdf

47. Jitsomwang S. How mandatory warning images on cigarette packages affect health perceptions and smoking avoidance in the Bangkok area. [Thesis in Thai]. Master's Thesis. Bangkok: Thammasat University; 2016. Available from: http://ethesisarchive.library.tu.ac.th/thesis/2016/TU_2016_5804010212_64 24_4480.pdf

48. Indonesia Ministry of Public Health. Notice of rules, procedures and conditions for the display and content of cigarette labels. 2009. Tobacco Products Control Act B.E. 2535 (A.D. 1992). Available from: https://www.tobaccocontrollaws. org/files/live/ Tha i 1 a n d / T h a i 1 a n d \% 20 \%20Cigarette\%20Label\%20Regs\%202009.pdf

49. Indonesia Ministry of Public Health. Notice of rules, procedures, and conditions for the display of images, warning statements, and contact channels for smoking cessation on cigarette labels. 2013. Tobacco Products Control Act B.E. 2535 (A.D. 1992). Available from: https://www.tobaccocontrollaws. org/files/live/Thailand/Thailand \%20-\%20 P\%26L\% 20Rules\%202013.pdf

50. Family Network Foundation [Internet]. 10 warning pictures on cigarette packs. 2010. [In Thai]. Accessed: 19 Apr 2018. Available from: http://www.familynetwork.or.th/content/10ภาพคำ เตือนบนซองบุหรี่

51. Isranews Agency [Internet]. Ministry of Public Health has 
issued a warning for the world's largest cigarette pack. 2013. Accessed: 20 Apr 2018. Available from: https://www.isranews.org/isranews-news/20463 - สธคลอดประกาศคำ เตือนซองบุหรี่ใหญ่ที่สุดในโลกแล้ว $-\mathrm{sp}-$ 690588681.html

52. Gendall P, Hoek J, Gendall K. Evaluating the emotional impact of warning images on young adult smokers and susceptible non-smokers. J Health Commun 2018;23:291-8.

53. Popova L, So J, Sangalang A, et al. Do emotions spark interest in alternative tobacco products? Health Educ Behav 2017;44:598-612.

54. Yamane T. Statistics, an introductory analysis. New York: Harper and Row; 1967.

55. Physicians for a Smoke-Free Canada [Internet]. Picture based cigarette health warnings: Research. Accessed: 21 Nov 2018. Available from: http://www.smoke-free.ca

56. Brown SL, Smith Z. The inhibitory effect of a distressing antismoking message on risk perceptions in smokers. Psychol Health 2007;22:255-68.

57. Keller PA, Block LG. Increasing the persuasiveness of fear appeals: the effect of arousal and elaboration. J Consumer Res 1996;22:448-59.

58. Kees J, Burton S, Andrews JC, et al. Understanding how graphic pictorial warnings work on cigarette packaging. J Public Policy Marketing 2010;29:265-76.
59. Farrelly M, Choiniere C. Experimental study of graphic cigarette warning labels. Contract No. HHSF-223-200910135G. Rockville: Food and Drug Administration; 2010. Available from: https://www.fda.gov/tobaccoproducts/research/research-experimental-study-graphiccigarette-warning-labels

60. Cameron LD, Pepper JK, Brewer NT. Responses of young adults to graphic warning labels for cigarette packages. Tob Control 2015;24:14-22.

61. Berg CJ, Thrasher JF, Westmaas JL, et al. College student reactions to health warning labels: Socio-demographic and psychosocial factors related to perceived effectiveness of different approaches. Prev Med 2011;53:427-30.

62. Pepper JK, Cameron LD, Reiter PL, et al. Non-smoking male adolescents' reactions to cigarette warnings. PLoS One 2013;8:e65533.

63. HFocus [Internet]. Investigations on Health Systems. 2017. [In Thai]. Accessed: 19 Aug 2018. Available from: https://www.hfocus.org/content/2017/05/13944

64. Li HCW, Chan SS, Lam TH. Smoking among Hong Kong Chinese women: behavior, attitudes and experience. BMC Public Health 2015;15:183.

65. Smith SY, Curbow B, Stillman FA. Harm perception of nicotine products in college freshman. Nicotine Tob Res 2007;9:977-82. 